\title{
PROFILE OF KERATOMYCOSIS IN A TERTIARY CARE TEACHING HOSPITAL IN WESTERN UTTAR PRADESH, INDIA
}

\section{Microbiology}

Vandana Sardana*

MD, Associate Professor, Department of Microbiology, Shri Ram Murti Smarak Institute of Medical Sciences, Bareilly-243202. *Corresponding Author

\section{Sameer R Verma}

MD, Professor, Department of Radiodiagnosis, Shri Ram Murti Smarak Institute of Medical Sciences, Bareilly- 243202.

\section{ABSTRACT}

Introduction- Fungal keratitis or keratomycosis refers to an infective process of the cornea caused by fungi capable of invading the ocular surface. Aims \& Objectives-i) To determine the frequency of fungal keratitis in clinically diagnosed cases ii)To identify the aetiological agents of keratomycosis. iii) To assess the precipitating factors associated with it. Method-A retrospective data of 2 years was analyzed to study the number of cases of fungal keratitis, from among the corneal scrapings submitted to the Department of Microbiology, examined for the presence of fungal elements by direct microscopic methods and for the fungal growth in culture. Results-The frequency of fungal keratitis in clinically diagnosed cases was $28.6 \%$. Among the positive cases, males outnumbered females with the ratio of 1.67:1. The maximum number of positive cases were seen in the age group of 21-30 years, followed by the age groups of 31-40 years and 11-20 years. The most common cause of fungal keratitis was Aspergillus flavus (31.25\%), followed by Aspergillus fumigatus (18.75\%), Fusarium solani and Candida albicans (12.5\% each ), and Cladophialophora bantiana, Curvularia, Mucor and Candida tropicalis (6.25\% each). Aspergillus species were found to be isolated from $50 \%$ of cases of keratomycosis. Filamentous fungi were predominantly associated with mycotic keratitis, accounting for $81.25 \%$ of cases, as compared to yeasts which had caused keratitis in $18.75 \%$ of cases. Amongst the cases of keratomycosis, all were positive for fungal growth on culture, out of which $81.25 \%$ cases were also positive for the presence of fungal elements on direct microscopy. Discussion: Keratomycosis is the leading cause of ocular morbidity worldwide, including India. Fungal agents causing keratitis should receive special attention due to their opportunistic behaviour and indolent course of disease. Lack of early diagnosis and treatment prelude the onset of complications, which may compromise the patient's vision and thereby the quality of life. Conclusion: Regular surveillance and scrutiny of mycotic keratitis is important and essential to understand the pattern of fungi, existing or emerging, so as to prevent the unnecessary and irrational usage of antibiotics.

\section{KEYWORDS}

Fungal keratitis, molds, yeasts, $\mathrm{KOH}$ mount, culture, Aspergillus, Fusarium

\section{INTRODUCTION:}

Mycotic keratitis is an invasive fungal infection of the cornea. ${ }^{1,2}$ Corneal ulcer is one of the major causes of ocular morbidity in developing countries and fungi are the main etiological agents of corneal ulceration in India. ${ }^{3,4,5}$ Fungi are ubiquitous organisms, present in environment as saprotrophs. ${ }^{1,2,6}$ Majority of the cases of keratomycosis are caused by hyaline fungi such as Aspergillus, Fusarium, Acremonium, Penicillium and Pseudallescheria. The phaeoid fungi such as Alternaria, Curvularia, Exserohilum and Bipolaris are the relatively uncommon causes of keratomycosis. ${ }^{1}$ These fungi usually cause infection when there is a breach in corneal epithelium following trauma but some of them may penetrate the intact cornea. ${ }^{6}$ World Health Organization reported that corneal diseases are the major cause of monocular blindness after cataract. Around 1.5 to 2 million new cases of corneal ulcer are reported annually. ${ }^{7}$ Risk factors for fungal keratitis are male gender, history of ocular trauma, chronic use of corticosteroids and systemic diseases, that impair the host immunity. ${ }^{8,9}$ In India, Fusarium and Aspergillus species are being frequently isolated from corneal ulcers, ${ }^{3,10-14}$ irrespective of the geographical location. This study has been carried out to determine the frequency of fungal keratitis in clinically diagnosed cases, ii) To identify the aetiological agents of keratomycosis. iii) To assess the precipitating factors associated with it at tertiary care teaching hospital in western Uttar Pradesh.

\section{MATERIALS AND METHOD:}

The retrospective study was done for the period of two years after approval from the institutional ethical committee.

Corneal scrapings taken in the ophthalmology department, from the clinically diagnosed cases of infectious keratitis were sent to the Microbiology department for processing. Patient's age, gender, occupation, history of any trauma, use of topical medicines or use of contact lens and ophthalmic ultrasound findings (wherever available) were recorded from the patient clinical records.

The corneal scrapings processed as per standard techniques. ${ }^{2,15,16}$ 1. Direct microscopy was performed for the presence of bacteria, fungus or parasite:

a. Potassium hydroxide (KOH) Mount- Wet mounts of corneal scrapings were prepared in $10 \% \mathrm{KOH}$. to observe the presence of fungal filaments b. Gram's staining was done for the evidence of any bacterial aetiology.

\section{Culture: $:^{2,15,16}$}

The material from corneal scrapings was inoculated directly onto sheep blood agar and chocolate agar in rows of ' $\mathrm{C}$ '- shaped streaks and incubated at $37^{\circ} \mathrm{C}$ for upto 48 hours. The portion of the sample was inoculated onto Sabouraud's dextrose agar (SDA) without cycloheximide in duplicate tubes and incubated at $25^{\circ} \mathrm{C}$ and $37^{\circ} \mathrm{C}$, respectively, for 4 weeks.

Identification of fungal growth was done as per standard mycological techniques: ${ }^{2,15,1}$

Molds were identified by their colony characteristics on SDA and sporulation pattern on lactophenol cotton blue mount. Slide cultures were put up for non-sporulating molds.

Yeasts were identified conventionally by their growth on SDA, germ tube test, microscopic findings on cornmeal agar, colony characteristics on Chrom agar sugar fermentation and assimilation tests, and by using Automated Vitek 2 YST identification card (bioMerieux, France), as per manufacturer's instructions.

\section{RESULTS:}

In the present study, corneal scrapings were obtained from a total of 56 clinically diagnosed cases of keratitis, out of which 34 were males and 22 were females.

Out of total of 56 samples, $16(28.6 \%)$ were positive for fungal growth, $7(12.5 \%)$, yielded bacterial growth and the remaining $33(58.9 \%)$, samples were culture sterile. Thus the frequency of fungal keratitis in clinically diagnosed cases was $28.6 \%$.

Among the positive cases of fungal keratitis, males (62.5\%) outnumbered females $(37.5 \%)$ with the ratio of $1.67: 1$ (Table 1$)$. The maximum number of positive cases were seen in age group of 21-30 years, followed by the age groups of $31-40$ years and $11-20$ years (Table 1).

The most common cause of fungal keratitis was Aspergillus flavus (31.25\%), followed by Aspergillus fumigatus (18.75\%), Fusarium solani and Candida albicans (12.5\% each), and Cladophialophora bantiana, Curvularia, Mucor and Candida tropicalis (6.25\% each) 
(Table 2). Aspergillus species were found to be isolated from $50 \%$ of cases of keratomycosis. Filamentous fungi were predominantly associated with mycotic keratitis, accounting for $81.25 \%$ of cases, as compared to yeasts which had caused keratitis in $18.75 \%$ of cases (Table 3).

Amongst the cases of keratomycosis $(n=16)$, all were positive for fungal growth on culture, out of which $81.25 \%$ cases were also positive for the presence of fungal elements on direct microscopy (Table 4).

The most common precipitating factor associated with fungal keratitis was prolonged usage of topical medications such as corticosteroids /antibiotics $(56.25 \%)$, followed by a trauma with vegetative matter $(31.25 \%)$, usage of contact lenses and previous corneal surgery (6.25\% each) (Table 5).

The ophthalmic ultrasound findings were available from the clinical records in 48 patients out of the 56 patients included in this study and were within normal limits in 42 patients with abnormality detected in six patients (cataract in four patients, and PVD and RD in one patient each).( Table 6 )

Table 1: Age and gender wise distribution of cases of fungal keratitis $(n=16)$

\begin{tabular}{|l|l|l|l|}
\hline Age (in years) & Total no. of positive cases & Male & Female \\
\hline $0-10$ & 0 & 0 & 0 \\
\hline $11-20$ & 3 & 3 & 0 \\
\hline $21-30$ & 5 & 3 & 2 \\
\hline $31-40$ & 4 & 2 & 2 \\
\hline $41-50$ & 2 & 1 & 1 \\
\hline $51-60$ & 1 & 1 & 0 \\
\hline$\geq 61$ & 1 & 0 & 1 \\
\hline Total & 16 & 10 & 6 \\
\hline
\end{tabular}

Table-2: Distribution of fungal agents isolated from the cases of keratomycosis $(n=16)$

\begin{tabular}{|l|l|l|}
\hline Fungal agent & $\begin{array}{l}\text { Number of } \\
\text { cases }\end{array}$ & $\begin{array}{l}\text { Percentage of cases } \\
\mathbf{( \% )} .\end{array}$ \\
\hline Aspergillus flavus & 5 & 31.25 \\
\hline Aspergillus fumigatus & 3 & 18.75 \\
\hline Fusarium solani & 2 & 12.5 \\
\hline Cladophialophora bantiana & 1 & 6.25 \\
\hline Curvularia & 1 & 6.25 \\
\hline Mucor & 1 & 6.25 \\
\hline Candida albicans & 2 & 12.5 \\
\hline Candida tropicalis & 1 & 6.25 \\
\hline
\end{tabular}

Table-3: Aetiology of mycotic keratitis :- Molds versus Yeasts $(\mathrm{n}=16)$

\begin{tabular}{|l|l|l|}
\hline Fungus & Number of cases & Percentage of cases (\%). \\
\hline Molds & 13 & 81.25 \\
\hline Yeasts & 3 & 18.75 \\
\hline
\end{tabular}

Table-4: Direct microscopy versus Culture $(n=16)$

\begin{tabular}{|l|l|l|}
\hline Test & $\begin{array}{l}\text { Number of } \\
\text { positive cases }\end{array}$ & $\begin{array}{l}\text { Percentage of positive } \\
\text { cases (\%). }\end{array}$ \\
\hline Direct microscopy & 13 & 81.25 \\
\hline Culture & 16 & 100 \\
\hline
\end{tabular}

Table 5: Precipitating factors associated with cases of keratomycosis $(\mathrm{n}=16)$

\begin{tabular}{|l|l|l|}
\hline Risk factor & $\begin{array}{l}\text { Positive cases } \\
(\mathbf{n = 1 6})\end{array}$ & Percentage (\%) \\
\hline $\begin{array}{l}\text { Prolonged usage of topical } \\
\text { medications }\end{array}$ & 9 & 56.25 \\
\hline Trauma with vegetative matter & 5 & 31.25 \\
\hline Usage of contact lens & 1 & 6.25 \\
\hline Previous corneal surgery & 1 & 6.25 \\
\hline
\end{tabular}

Table 6: Ophthalmic USG findings in clinically diagnosed cases of infectious keratomycosis $(n=48)$

\begin{tabular}{|l|l|}
\hline Ultrasound findings & No. of patients $(\%)$ \\
\hline Normal & $\mathbf{4 2}(\mathbf{8 7 \%})$ \\
\hline Cataract & $\mathbf{4}(\mathbf{8 \%})$ \\
\hline Posterior vitreous detachment & $\mathbf{1 ( 2 . 5 \% )}$ \\
\hline Posterior retinal detachment & $\mathbf{1 ( 2 . 5 \% )}$ \\
\hline
\end{tabular}

\section{DISCUSSION:}

Despite advancements in the ocular treatment strategies, fungal keratitis remains an important cause of ocular morbidity. In the present study, the frequency of fungal keratitis in clinically diagnosed cases was found to be $28.6 \%$. In India, the prevalence of fungal corneal ulcer is estimated as $44-47 \% .{ }^{10}$ Keratomycosis comprises of at least $50 \%$ of all culture positive cases in India. ${ }^{4}$ The incidences of mycotic keratitis have been documented to be variable across the various states of India: southern and western India with $36.7 \%{ }^{17}$ and $36.3 \%{ }^{17,18}$ northern $(7.3 \%)$, northeastern $(25.6 \%)$, and eastern India $(26.4 \%){ }^{19-2}$

An increase in occurrence of fungal keratitis, in India, is attributed to tropical climate and farming, as one of the main occupations, which poses a high risk due to vulnerability for occupational trauma, especially by organic materials and sand particles.

Among the positive cases of fungal keratitis, males $(62.5 \%)$ outnumbered females $(37.5 \%)$ with the ratio of 1.67:1 (Table 1). Our data is consistent with the study done by Gupta A et al. ${ }^{8}$ in which incidence of keratomycosis was more in males $(63.6 \%)$ than in females (36.4\%). A study done in Chandigarh by Chander J et al. ${ }^{22}$ also reported the male predominance in cases of fungal keratitis.

We can consider that the higher rate of occurrence of keratitis in males is attributed to their more indulgence in outdoor activities and field work related to agriculture. ${ }^{6}$

In our study, maximum number of positive cases were seen in age group of 21-30 years, followed by the age groups of 31-40 yrs and 1120 years (Table 1), indicating occurrence of keratomycosis in young to middle aged population, which is the most common actively working age group.

Gupta A et al. ${ }^{8}$ found that majority of fungal ulcers were seen in the age group of 21-40 years. Whereas Chander et $\mathrm{al}^{22}$ from Chandigarh reported that $56.67 \%$ cases of fungal keratitis belonged to the age group of 20-49 years, recent study by Rohilla et $\mathrm{al}^{24}$ in Uttarakhand described 41-60 years was the age group in which most of the keratitis cases were recorded $(53 \%)$.

In the present study prolonged usage of topical medications such as corticosteroids /antibiotics $(56.25 \%$ ), and trauma with vegetative matter $(31.25 \%)$ were the common predisposing factors, followed by usage of contact lenses and previous corneal surgery $(6.25 \%$ each) (Table 5). Similar observations have also been made by other studies. ${ }_{1,6,8,25,26}$ Antibiotics are known to alter normal local microbial flora and steroids have been the culprit to alter corneal metabolism, and thus changing the defense mechanism. ${ }^{8}$

As far as occupational history is concerned, mycotic keratitis was more common in field workers such as farmers, which coincides with the findings in other studies. ${ }^{26-29}$

Fungal spores are pervasive and ubiquitous in nature. Keratomycosis in farmers /agriculturists is related to the presence of fungal spores on deciduous and senile vegetations.

Amongst the cases of keratomycosis $(\mathrm{n}=16)$, all were positive for fungal growth on culture, out of which $81.25 \%$ cases were also positive for the presence of fungal elements on direct microscopy, thus indicating that culture is more sensitive than microscopy ( Table 4). Similar observations were also made by Gupta A et al. ${ }^{8}$ However, a study done in Chandigarh reported that $46.86 \%$ cases were negative for fungal growth on culture despite positive findings on direct microscopy

In our study, the commonest cause of fungal keratitis was Aspergillus flavus (31.25\%), followed by Aspergillus fumigatus (18.75\%), Fusarium solani and Candida albicans (12.5\% each), and Cladophialophora bantiana,Curvularia, Mucor and Candida tropicalis $(6.25 \%$ each). Aspergillus species were found to be responsible for $50 \%$ of cases of keratomycosis. (Table 2 ).

Filamentous fungi were predominantly associated with mycotic keratitis, accounting for $81.25 \%$ of cases, as compared to yeasts which had caused keratitis in $18.75 \%$ of cases (Table 3 ).

The fungi that are isolated from corneal scrapings are, at many occasions, the part of normal local microbial flora, and also the saprophytes in the soil and environment. ${ }^{8}$ 
In 2000, a study done in Delhi by Gupta A et al. ${ }^{8}$ found Aspergillus species as the most frequent cause of keratitis, followed by $F$. solanii . Yeasts were isolated in $14.3 \%$ of cases and filamentous fungi in $85.5 \%$ of $\operatorname{cases}^{8}$, which are consistent with our observations in the present study.

Another study done in north India ${ }^{30}$, in 2005, also reported Aspergillus species as the commonest cause of fungal keratitis accounting for $41 \%$ of cases.

In 2012, authors in western India ${ }^{31}$ isolated Aspergillus species in $40 \%$ of cases.

However, various studies done in south India ${ }^{17,32,33}$ and recently in Northern India ${ }^{24}$ found Fusarium species to be the most common cause of fungal keratitis.

Doczi $I$ et al. reported a case of keratomycosis caused by a mixed infection involving Fusarium verticillioides along with Staphylococcus epidermidis, an $\alpha$ haemolytic streptococcus and Propionibacterium acnes, in Hungary in $2004 .{ }^{13}$ However, Tanure MA et al. ${ }^{34}$ found Candida albicans $(46 \%)$ as the commonest cause of mycotic keratitis in Philadelphia, in 2000.

Studies ${ }^{35-37}$ have reported Aureobasidum pullulans as the cause of keratitis following surgical interventions.

Hyaline fungi (Aspergillus, Fusarium species) have been reported to be commonly associated with corneal ulcers, followed by dematiaceous fungi (Curvularia and Bipolaris species). Candida species have been found to have a low preponderance in developing countries. ${ }^{38,39}$

In contrast to non-dermatophyte molds associated with mycotic keratitis, a study done in New Delhi, by Sharma Y et al.$^{26}$ had reported Trichophyton species as a potent fungal agent capable of causing keratitis.

Fungal agents causing keratitis should receive special attention due to their opportunistic behaviour and indolent course of disease. Lack of early diagnosis and treatment prelude the onset of devastating complications, which may compromise the patient's vision and thereby the quality of life.

Figures

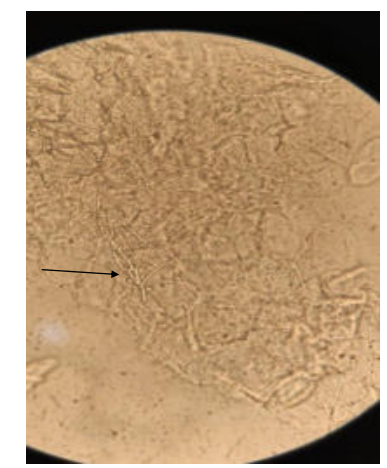

Figure 1: Corneal scrapings showing fungal hyphae on $10 \% \mathrm{KOH}$ wet mount (400x) (arrowed)

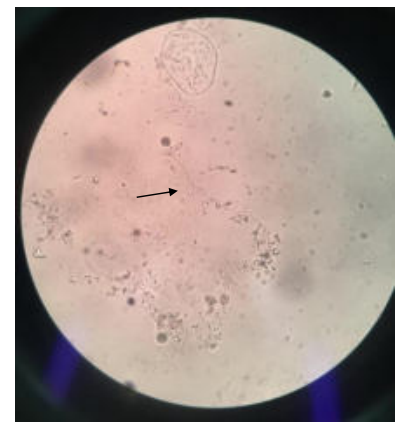

Figure 2: Corneal scrapings showing budding yeast cells with pseudohyphae on $10 \% \mathrm{KOH}$ wet mount (400 x ) (arrowed)

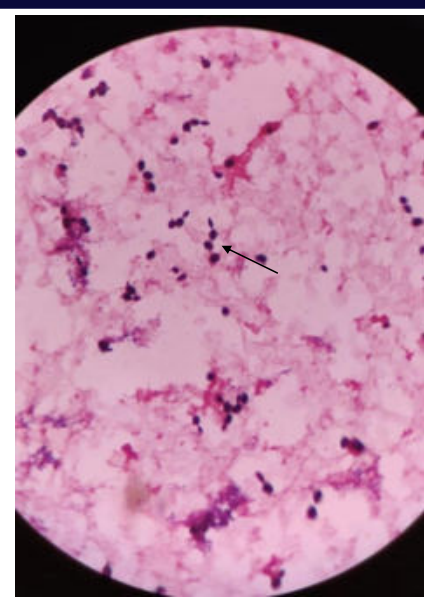

Figure 3 : Corneal scrapings showing budding yeast cells on Gram's stain $(1000 x)$ (arrowed)

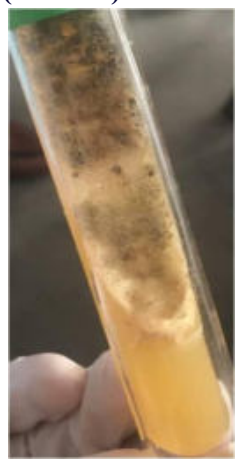

Figure 4: Aspergillus flavus growth on SDA

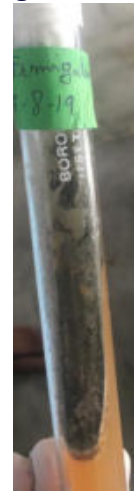

Figure 5: Aspergillus fumigatus growth on SDA

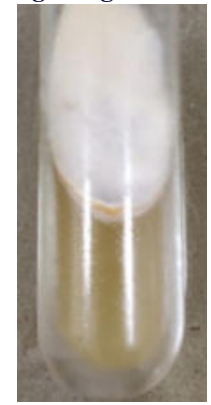

Figure 6: Fusarium solani growth on SDA

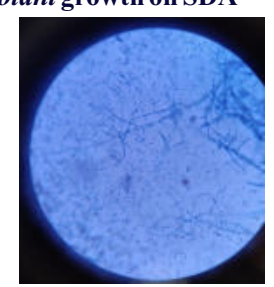

Figure 7: Fusarium solani on LCB mount (400 x) 
CONCLUSIONS:

Regular surveillance and scrutiny of mycotic keratitis is important and essential to understand the pattern of fungi, existing or emerging, so as to prevent the unnecessary and irrational usage of antibiotics.

\section{Limitations:}

Antifungal susceptibility testing could not be done due to limited resources. Failure of microorganisms to grow in culture would have been amended by the use of molecular methods.

\section{REFERENCES:}

1. Thomas PA. Fungal infections of the cornea. Eye (Lond). 2003;17:852-6

2. Chander J, Texbook of Medical Mycology, 4th edition. New Delhi, India: Jaypee Brothers Medical Publishers ; 2017.

3. Srinivasan M. Fungal keratitis. Curr Opin Ophthalmol 2004:15:321-7.

4. Thomas PA. Current perspective in ophthalmic mycosis. Clin Microbiol Rev 2003:16:730-97

5. Gopinathan U, Sharma S, Garg P, Rao GN. Review of epidemiological features, microbiological diagnosis and treatment outcome of microbial keratitis: Experience of over a decade. Indian J Ophthalmol . 2009;57:273-9.

6. Chandra A, Gupta MK, Prakash D, Tilak R, Maaurya OPS. Diagnosis of keratomycosis: an update. International Journal of Current Research. 2013; 5 (11): 3474-3479.

7. Whitcher JP, Srinivasan M, Upadhyay MP. Corneal blindness: a global perspective. Bull World Health Organ. 2001;79(3):214-21.

8. Gupta A, Capoor MR, Gupta S, Kochhar S, Tomer A, Gupta V. Clinico-demographical profile of Cratomycosis in Delhi, North India Indian J Med Microbiol 2014;32:310-4.

. Verghese S. Post traumatic fungal keratis caused by Acremonium recifi. Indian $J$ Pathol Microbiol .2010; 53:587-8.

10. Srinivasan M, Gonzales CA, George C, Cevallos V, Mascarenhas JM, Asokan B, Wilkins J, Smolin G, Whitcher JP. Epidemiology and aetiological diagnosis of corneal ulceration in Madurai, South India. British Journal of Ophthalmology. 1997; 81 (11): 965-971.

11. Lalitha P, Shapiro BL, Srinivasan M, Prajna NV, Acharya NR, Fothergill AW et al. Antimicrobial susceptibility of Fusarium, Aspergillus, and other filamentous fungi isolated from keratitis. Arch Ophthalmol. 2007;125:789-93.

12. Bharathi MJ, Ramakrishnan R, Vasu S, Meenakshi, Palaniappan R. Aetiological diagnosis of microbial keratitis in South India - a study of 1618 cases. Indian Journal of Medical Microbiology. 2002; 20 (1):19-24.

13. D'oczi I, Gyetvai T, Kredics L, Nagy E. Involvement of Fusarium spp. in fungal keratitis. Clinical Microbiology and Infection. 2004;10(9):773-776.

14. Bharathi MJ, Ramakrishnan R, Meenakshi R, Mittal S, Shivakumar C, Srinivasan M. Microbiological diagnosis of infective keratitis : comparative evaluation of direct microscopy and culture results. British Journal of Ophthalmology. 2006 ;90 (10): $1271-1276$

15. Moore GS, Jaciow DM. Mycology for the Clinical Laboratory. Reston, Virginia: Reston Publishing Company Inc.; 1979 .

16. Winn W, Allen S, Janda W, Koneman E, Procop G, Schreckenberger P. et al. (eds.) Koneman's Color Atlas and Textbook of Diagnostic Microbiology. 6thedition. Philadelphia: Lippincott Williams \&Wilkins; 2006

17. Bharathi MJ, Ramakrishnan R, Vasu S, Meenakshi R, Palaniappan R. Epidemiological characteristics and laboratory diagnosis of fungal keratitis. A three-year study. Indian Journal of Ophthalmology. 2003; 51(4):315-321.

18. Deshpande SD, Koppikar GV. A study of mycotic keratitis in Mumbai. Indian Journal of Pathology and Microbiology. 1999; 42 (1):81-87.

19. Chander J, Sharma A. Prevalence of fungal corneal ulcers in Northern India. Infection. 1994; 22 (3):207-209.

20. Saha S, Banerjee D, Khetan A, Sengupta J. Epidemiological profile of fungal keratitis in urban population of West Bengal, India. Oman J Ophthalmol. 2009; 2(3):114-118

21. Rautaraya B, Sharma S, Kar S, Das S, Sahu SK. Diagnosis and treatment outcome of mycotic keratitis at a tertiary eye care center in eastern India. BMC Ophthalmology. 2011; 11(1): 39

22. Chander J, Singla N, Agnihotri N, Arya SK, Deep A. Keratomycosis in and around Chandigarh: A five year study from a north Indian tertiary care hospital. Ind J Pathol Microbiol.2008; 51:304-6.

23. Kotigadde S, Ballal M, Jyothirlatha, Kumar A, Srinivasa R, Shivananda PG. Mycotic keratitis: Astudy in coastal Karnataka. Ind J Ophthalmol .1992;40:31-3.

24. Rohilla R, Meena S, Mohanty A, Gupta N, Kaistha N, Gupta P, Mangla A, Singh A Etiological spectrum of infectious keratitis in the era of MALDI-TOF-MS at a tertiary care hospital. J Family Med Prim Care 2020;9:4576-81

25. Bhartiya P, Daniell M, Constantinou M, Islam FM, Taylor HR. Fungal keratitis in Melbourne. Clin Experiment Ophthalmol. 2007;35:124-30.

26. Sharma Y, Jain S, Jayachandran. Keratomycosis: Etiology, Risk Factors and Differential Diagnosis- A Mini Review on Trichophyton spp. Journal of Clinical and Diagnostic Research. 2014;8(10):1-2.

27. Venugopal PL, Venugopal TL, Gomathi A, Ramakrishna ES, Ilavarasi S. Mycotic keratitis in Madras. Indian J Pathol Microbiol.1989;32:190-7.

28. Sathyanarayan MS, Suresh BS, Surekha YA, Mariraj J, Krishna S. Epidemiology and aetiological diagnosis of keratomycosis in a tertiary care hospital in North Karnataka. Int JCurr Res Rev. 2013;5:92-7.

29. Saha R, Das S. Mycological profile of infectious keratitis from Delhi. Indian J Med Res. 2006;123:159-64.

30. Chowdhary A, Singh K. Spectrum of fungal keratitis in North India. Cornea.2005;24:815 .

31. Jadhav SV, Gandham NR, Misra RN, Ujagare MT, Sharma M, Sardar M. Prevalence of fungal keratitis from tertiary care hospital from western part of India. Int J Microbiol Res. 2012;4:207-10.

32. Lalitha P, Shapiro BL, Srinivasan M, Prajna NV, Acharya NR, Fothergill AW et al. Antimicrobial susceptibility of Fusarium. Aspergillus, and other filamentous fungi isolated from keratitis. Arch Ophthalmol . 2007;125:789-93.

33. Anusuya D, Ambica R, Nagarathnamma T. The epidemiological features and laboratory diagnosis of keratomycosis. Int J Biol Med Res. 2013;4:2879-83

34. Tanure MA, Cohen EJ, Sudesh S, Rapuano CJ, Laibson PR. Spectrum of fungal keratitis atWills Eye Hospital. Cornea. 2000;19(3):307-12.

35. Panda A, Das H, Deb M, Khanal B, Kumar S. Aureobasidium pullulans keratitis. Clin Experiment Ophthalmol.2006;34:260-4

36. Chawla B, Sharma N, Titiyal JS, Nayak N, Satpathy G. Aureobasidium pullulans keratitis following automated lamellar therapeutic keratoplasty. Ophthalmic Surg Lasers Imaging. 2010;9:1-3.

37. Maverick KJ, Conners MS. Aureobasidium pullulans fungal keratitis following LASEK. J Refract Surg. 2007;23:727-9.

38. Basak SK, Basak S, Mohanta A, Bhowmick A. Epidemiological and microbiological diagnosis of suppurative keratitis in gangetic West Bengal, Eastern India. Indian $J$ Ophthalmol. 2005:53:17-22

39. Vijaya D, Sumathi, Malini. Keratomycosis due to Fusarium oxysporum-A case report. Indian JPathol Microbiol. 2001; 44:337-8. 